\title{
IMPROVING THE RELEVANCE OF SPEECH-LANGUAGE PATHOLOGY \& AUDIOLOGY RESEARCH AND PRACTICE
}

\author{
Kathard, H., Naude, E., Pillay, M \& Ross, E.
}

Editorial Board: South African Journal of Communication Disorders

\section{How do the professions of Speech-Language Pathology and Audiology practice? How do they produce their knowledge?}

The focus of this article is on the nature of research within the joint professions of Speech-Language Pathology (SLP) and Audiology. Specifically, we foreground the issue of relevance within professional research for professional practice. In doing so, we not only seek to promote a certain symbiosis between researchers and practitioners but also to promote greater competence toward improving the lives of people living with communication and/or swallowing disorders - which direct its research and practice foci. Essentially, SLP and Audiology's project is really about accessing the lived experience of people with communication/swallowing disorders. As lives are deeply related to the professions' foci, then it is reasonable to assume that its research and practice ought to engage what is of relevance to people and their lives. Gender, race, socio-economic status, culture, political determinants and such like are interpenetrating factors that determine one's experiences of, for example, living with an acquired language disorder. Predominantly, how has SLP and Audiology researched its foci? Mainly, we have researched the pathology by sanitizing peoples' social, political and cultural influences of their lives.

Historically, research for and within the professions have relied on good empirical, scientific methods to situate communication disorders. For example, in perusing publications associated with the beginnings (early $19^{\text {th }}$ Century) of SLP and Audiology research in the western world it is not unusual to encounter articles with titles such as:

- Observations on the History, Use, and Construction of Obturators, or What Have Hitherto Been Called in This Country Artificial Palates (Snell, 1824)

- Clinical report on Robert Bates' cure for stammering (Meigs, 1852)

- Mutilation of Stutterers. Surgical Operations which Have Been Performed for the Cure of Defects of Speech (Werner, 1881)

- The Possibility of Obtaining Marked Improvement in the Treatment of Deafness and Supposed Deaf-Mutism by Acoustic Gymnastics; A System of Vocal Training of the Auditory Nerve as Advocated by Urbantschitsch, of Vienna (Goldstein, 1895)

Writing styles aside, these titles reflect the way SLP and Audiology have developed their knowledge with the use of an empirical, positivist scientific frame which positions:

- reality as apprehensible, driven by natural laws and mechanisms (deterministic) and therefore reducible to parts which may be manipulated in an objective fashion.

- truth as existing outside of the researcher, and accessible via various objective techniques, and

- uses methods which emphasise experiments, the predictability of phenomena, allows for the testing of hypotheses and controls for confounding conditions.

Empiricism is preferred and valued as a research and practice orientation by SLP and Audiology practitioners and is used to focus the body as the site of prime interest. In referring to communication via this biological metaphor of the body; 'assessment', 'treatment', 'diagnoses' and 'prognoses' are now well established SLP and Audiology clinical frameworks. As such, good professional research is regarded as that which not only promotes the use of logical rationality, objectivity, causeeffect relationships, and experimental verification amongst a plethora of similar axioms; but also one understands people with communication disorders from a biological, medicallyorientated perspective. At its core, across practice sites in education or health care, the professions engage a medical gaze (Foucault, 1976) to research and practice.

The use of highly valued empirical research methodologies has functioned to develop our professional interests. For SLP and Audiology, as it is with other caring professions, research meets several key professional development functions. In the first instance, doing research fulfils practitioners' ethical obligations to contribute to their professions' knowledge base. Research is the dominant, usual method of sharing knowledge amongst professionals. Furthermore, this latter function is related to the understanding that professional research and practice ought to nurture and inform each other. While sensible, the reciprocal nature of the practice-research relationship does, however, require optimizing. Indeed, Kamhi (1999) exhorted researchers and clinicians to work together, not only to improve clinical practice through research, but also to make researchers more responsive to the needs of practitioners.

It is a widely held expectation that research itself once disseminated, shared and applied can enhance the effectiveness of practice. Currently, this sharing of research is placed in bare tension with the trend toward evidence based practice (EBP). Strenuous demands are placed on practitioners to test and evaluate what was previously recognised as 'best practice'. Practitioners have to follow clinical research literature in order to evaluate the relevance of the findings and make informed decisions to the benefit of the families and communities they serve (Bothe, 2004). According to Kamhi (1999) practitioners are well qualified to evaluate the effectiveness of new approaches suggested by research findings. In fact, practitioners are becoming ever more critical of activities not grounded in research-proven evidence. Therefore, the relationship between research and practice which is implicit in EBP also guides relevant research and accountable clinical practice for practitioners in South Africa (SA) and elsewhere. The methodological shape of EBP is inextricably intertwined with the professions' adoption of empirical research methodologies. 
It may be said that, thus far, empirical research has been an excellent vehicle without which SLP and Audiology may not have developed their current status as valid professions working with speech, language, voice, hearing and swallowing disorders. However, as we use empirically orientated frameworks such as EBP, professional research and practice must consider not only that evidence is necessary to develop practice; but also how practitioners' use evidence in ways that bear relevance to the lives of people they encounter in their clinical practice. As such, the utility value of our research, our professional knowledge base is brought into question.

For SLP and Audiology most professional knowledge is based on research with mainly male, urban, middle-class, Judeo -Christian, European language speakers (Taylor, 1986; Pillay, 1997; Marshall, Goldbart \& Evans, 2004). The adequacy (and relevance) of our research for all aspects of our professional work becomes dubious when we consider SLP and Audiology across the world's social, cultural, economic and political realities. For the majority world populations, most who live in poverty, it may be said that our research inadequately supports the needs of people in societal "black holes" (Soludo, 2001). Such people refer to those living in indigenous Australian communities, American ghettos, Indian slums, Emirates' labour camps and South African informal settlements. Post-apartheid SA has, as it is with other world democracies like India, Brazil and America; provided us with an opportunity to re-assess how, especially residents of societal black holes, may benefit from grand notions of democracy, equality, and anti-discrimination. These political ideologies affect everything we do, including our professional research and clinical practices.

To structure the implementation of democratic ideologies international organizations have developed several strategies to generate practices that address our world's social, political and cultural realities. For example, as health care practitioners, we are urged to pursue the collective wishes of the world as stated within the United Nation's (UN) Millennium Development Goals (UN, 2005). SLP research and practice ought to be configured in relation to the eight millennium development goals which range from the eradication of extreme poverty and hunger to the development of global partnerships for development. Therefore we should be guided by these priorities to help create a more equitable world. And as we do this, we should direct ourselves toward re-positioning our dominant medical understanding of disability within a social model that emphasizes human functioning as promoted by the International Classification of Functioning (WHO, 2001). Betwixt and between these world directives are issues of deep social and political concerns. What SLP and Audiology practitioners need to ask is: Should we be involved in addressing such social and political issues? Should we not just stay out of politics? Perhaps we need to clearly demarcate issues of professional science from political issues. Indeed, it may be argued that sexism, racism, homophobia, poverty and such issues are really outside the professions' domain of practice.

Almost thirty years ago, a similar argument was presented at an American Speech and Hearing Association's (ASHA) Convention in 1968. Orlando Taylor, a pre-eminent SLP in multicultural practice, explicitly linked his professional development to the greater political events of the time, i.e. a time when America was experiencing "...severe national discord over the Vietnam War and civil unrest by Blacks in numerous urban centers" (Taylor, 1986, p.2). Taylor argued that:

“...professional organizations should articulate a point of view on the important social and political issues of the day, making it possible for the corpo- rate body to influence decisions...I urge the American Speech and Hearing Association to provide aggressive leadership for moral, ethical, and judicial behavior in areas of significant social significance..."

(Taylor, 1986, p.2)

Taylor presented the above argument to John Michel (University of Kansas, USA) who responded with the following:

"It is unwise to jeopardize the purely professional nature of ASHA and the harmony among our Members by introducing current issues outside the realm of speech and hearing. It is both healthy and admirable that individual Members are sensitive to social issues and have the courage to organize opinion against unsatisfactory aspects of our society."

(Taylor, 1986, p. 2)

In essence, Michel argued that, while being sensitive, professionals should not be involved in engaging social, political, and cultural issues. Of course, SLP and Audiology has always focused on cultural, social, political, gender and related issues. It is just that this focus is largely untheorised as politically situated even though it has produced knowledge predominantly rooted in, and beneficial to, politically dominant populations of the world. However, as citizens of a world populated by a diversity of classes, genders, races, cultures and so on; SLP and Audiology practitioners must necessarily concern themselves with the everyday, lived experiences of most of the world's peoples. When considering the nature of the relationship between practice and research (or between practitioner and researcher) a basic premise ought to be considered, viz.: the coincidence of researchers' and practitioners' realities with the realities of majority world populations. Researchers and practitioners alike must ask: Is evidence from professional research that is dominantly based on minority world populations such as Caucasian, middle-class, monolingual, English-speakers relevant for practice with majority world populations? Locally, for $S A$, what would it mean to practice SLP and Audiology in relation to issues of poverty? What of SLP and Audiology research when we consider the burden of diseases such as tuberculosis, AIDS/HIV or malaria?

Indeed, the kind of engagement required involves more than relocating services to community clinics or re-focusing an empirical research lens to, for example, Black African languages. All this may serve to do is re-produce the same kind of restrictive ways of knowing, the same level of knowledge utility. Here, the question raised is really not about 'culture' or 'race' or 'politics' and suchlike. Rather, it is about the science we use to engage the issues. As a cultural artifact in itself empirical science must be considered for its usefulness to move the profession into the millennium. Perhaps, the time has come to listen to Taylor and consider ways in which we research and practice. While, Michel's sentiment may remain within professional ideologies and practices, the profession may still need to explore its response relative to "...moral, ethical, and judicial behavior in areas of significant social significance..." The question now is: can we rely on an empirical science to enable us to adequately engage what are issues of social justice?

In SA, policy changes have provided a fertile conceptual resource for the profession to consider issues of social justice. Equality and anti-discrimination, Ubuntu/human dignity and respect, democracy, equity, transparency and accountability are all excellent signposts for the professions' researchers and/or practitioners to consider when thinking about social justice. 
While our local focus is on how we live with the contradictions of 'colour' (an ideological issue) we are really engaged in a broader project of humanity. Ours is a political-social experiment that focuses how we relate to each other because of our social conditioning and of our political condition. The world has a pointed interest in SA for how we develop our human relationships, our humanity. Our policies, our political project is actually a world project because South African policies have largely been imagined around how we exist as people. Furthermore, although SLP and Audiology practices vary internationally and are shaped by local contextual realities, the core historical-cultural medical professional practices remain entrenched (Pillay, 1997). In this way, as SLP and Audiology researchers/practitioners we may comfortably and ably dialogue with colleagues in other countries who share similar aspirations through international organizations that espouse liberal, democratic ideologies such as the World Bank, the United Nations (UN), and the World Health Organisation (WHO).

In the last few decades, several shifts in professional practice have occurred that may (retrospectively) be understood relative to democratic ideologies engendered within global development maps like the Millennium Development Goals and the International Classification of Functioning. Consider the focus on $\mathrm{mul}$ ticultural/multilingual practice which has challenged the dominant theoretical frames that did not consider the implications of non-White, non-English, and non-middle class values. An associated trend has been the development of ecological frameworks of practice such as whole language (Norris, 1990) and ecological audiology (Borg, 1998). Similarly, socially-orientated services such as community based rehabilitation (CBR) and/or or primary health care (PHC) within SLP and Audiology has promoted services to people with communication disorders in their homes and/ or via community structures (Jager, 1994; Wirz, 1995). Significantly, qualitative methods have been explored for practice within SLP and Audiology (Eastwood, 1988; Hetu, Riverin, Lalande, Getty, \& St-Cyr, 1998). Qualitative methods have gained measured success with the recognition of strategies such criterion referencing (Westby, StevensDominguez \& Oetter, 1996) and research (Kearns, 1999). Finally, narrative methods of practice have slowly been gaining credence since at least the late 1990 's within, for example, the field of aphasia (Parr, Byng, Gilpin \& Ireland, 1997).

These shifts link to sources 'outside' of the professions' own peculiar foci. For example, they draw on inspirations from the social sciences, education, social anthropology, philosophy and suchlike. They also serve as a challenge to the professional knowledge base by presenting concepts that must actively account for a range of contextual factors such as culture, race, social and economic factors. If suitable, how may we use qualitative research to effect changes in practice? What about the use of randomized control trials when working with the multidimensional complexities of people that inherently defy controlling? Are all research questions suited to ethnographic studies, life histories and similar phenomenological approaches? What about the relevance of research that uses good empirical science that enables us to manage people with swallowing disorders? Can hearing disorders benefit from ecological audiology? What lies beyond electrophysiological assessments of hearing? How do SLPs and Audiologists work with 'normal' people to prevent disorders? How do we research non-curative, preventative ways of working? What remains is for SLP and Audiology to develop ways of guiding relevant research for relevant practice. In the next few responses, leading researchers and/or practitioners highlight their thoughts in relation to these questions. They contribute solutions to the dilemmas and theoretical-practical issues raised throughout this article.
Borg, E. (1998). Audiology in an Ecological Perspective - Development of a Conceptual Framework. Scandinavian Audiology, 27, Supplement no. 49, 132-139.

Bothe, A.K. (2004). Evidence-based treatment of stuttering - empirical bases and clinical applications. Mahwah, NJ: Lawrence Erlbaum Associates.

Eastwood, J. (1988). Qualitative research: An additional research methodology for Speech Pathology? British Journal of Communication Disorders, 23, 171-184.

Foucault, M. (1976). The Birth of the Clinic: An Archaeology of Medical Perception. Tavistock: London.

Goldstein, M. (1895). The possibility of obtaining marked improvement in the treatment of deafness and supposed deaf-mutism by acoustic gymnastics; a system of vocal Training of the Auditory Nerve as Advocated by Urbantschitsch, of Vienna. Archives of Otolaryngology, XXIV.

Hetu, R., Riverin, L., Lalande, N., Getty, L. \& St-Cyr, C. (1998). Qualitative analysis of the handicap associated with occupational hearing loss. British Journal of Audiology, 22, 251-264.

Jager, G.W. (1994). Community based education in Speech Pathology and Audiology at the University of Durban-Westville in an underserved community. South African Journal of Communication Disorders, 41, 93-103.

Kamhi, A.G. (1999). To use or not to use: factors that influence the selection of new treatment approaches. Language, Speech, and Hearing Services in Schools, 30(1), 92-98.

Kearns, K.P. (1999). Qualitative research methods in Aphasia: A welcome addition. Aphasiologv, (13), 9-11, 649-650.

Marshall, J., Goldbart, J. \& Evans, R. (2004). International students of Speech andLanguage Therapy in the UK: Do we meet their needs? International Journal of Language \& Communication Disorders, 39 (2), 269-284.

Meigs, J. (1852). Clinical Report on Robert Bates' Cure for Stammering. Philadelphia, PA: Clinic of Jefferson Medical College: Surgeon General's Office Library.

Norris, J. A. (1990). Clinical Forum, Language, Speech, and Hearing Services in Schools, 21, 205.

Parr, S., Byng, S., Gilpin, S., \& Ireland, C. (1997). Talking about Aphasia. Open University Press: UK.

Pillay, M. (1997). Speech-Language Therapy and Audiology: Practice with a Black African First Language Clientele. Unpublished masters dissertation. University of Durban-Westville: South Africa.

Snell, J. (1824) Observations on the History, Use, and Construction of Obturators, or What Have Hitherto Been Called in This Country Artificial Palates. Collins \& Collins: London.

Soludo, C.C. (2001). Disputing Castellian Globalisation for Africa. In J. Muller, N. Cloete, \& S. Badat (Eds), Challenges of Globalisation: South African Debates with Castells. Maskew Miller Longman: Cape Town.

Taylor, O.L. (ed.) (1986). Nature of Communication Disorders in Culturally and Linguistically Diverse Populations, College-Hill, San Diego.

United Nations Department of Economic \& Social Affairs and the United Nations Department of Public Information (2005). Millennium Development Goals: Progress Chart. United Nations: Geneva [September 2005].

Werner, E.S. (1881). Mutilation of stutterers. Surgical operations which have been performed for the cure of defects of speech. The Voice, 3 (9), 127-128.

Westby, C., StevensDominguez, M., \& Oetter, P. (1996). A performance/ competence model of observational assessment. Language, Speech and Hearing Services in Schools, 27, 144-156.

Wirz, S. (1995). Opportunities and responsibilities towards people with communication disorders in less developed Countries. Caring to Communicate: Proceedings of the Golden Jubilee Conference, Royal College of Speech and Language Therapists, London: U.K, 459-465.

World Health Organisation (2001). International Classification of Functioning, Disability and Health. WHO: Geneva. 